Article

\title{
A Comparative Study of E-Beam Deposited Gate Dielectrics on Channel Width-Dependent Performance and Reliability of $a$-IGZO Thin-Film Transistors
}

\author{
Gwomei Wu ${ }^{1,2, *}$, Anup K. Sahoo ${ }^{1}$, Dave W. Chen ${ }^{2}$ and J. W. Chang ${ }^{2}$ \\ 1 Institute of Electro-Optical Engineering, Chang Gung University, Taoyuan 333, Taiwan; \\ anup140387@gmail.com \\ 2 Chang Gung Memorial Hospital, Keelung 204, Taiwan; mr5181@cgmh.org.tw (D.W.C.); \\ flyinwei@gmail.com (J.W.C.) \\ * Correspondence: wu@mail.cgu.edu.tw; Tel.: +886-3-211-8800
}

Received: 26 October 2018; Accepted: 7 December 2018; Published: 9 December 2018 updates

\begin{abstract}
A comparative study on the effects of e-beam deposited gate dielectrics for amorphous indium gallium zinc oxide ( $a$-IGZO) thin-film transistors (TFTs) has been carried out using $\mathrm{SiO}_{2}$, $\mathrm{Si}_{3} \mathrm{~N}_{4}$, and $\mathrm{Ta}_{2} \mathrm{O}_{5}$ dielectric materials. The channel width dependent device electrical performances were investigated using three different sizes of $500 \mu \mathrm{m}, 1000 \mu \mathrm{m}$, and $1500 \mu \mathrm{m}$. The reliability characteristics were revealed by the threshold voltage variation and drain current variation under positive bias stress. The e-beam deposited high-k dielectric $\mathrm{Ta}_{2} \mathrm{O}_{5}$ exhibited the highest stability at the stress voltage of $3 \mathrm{~V}$ for $1000 \mathrm{~s}$ due to its high capacitance density at $34.1 \mathrm{nF} / \mathrm{cm}^{2}$. The threshold voltage variation along the channel width decreased from $\mathrm{SiO}_{2}$, then $\mathrm{Si}_{3} \mathrm{~N}_{4}$, to $\mathrm{Ta}_{2} \mathrm{O}_{5}$, because of the increased insulating property and density of capacitance. The $\mathrm{SiO}_{2}$-based $a$-IGZO TFT achieved a high field effect mobility of $27.9 \mathrm{~cm}^{2} / \mathrm{V} \cdot \mathrm{s}$ and on-off current ratio $>10^{7}$ at the lower channel width of $500 \mu \mathrm{m}$. The gate leakage current also decreased with increasing the channel width/length ratio. In addition, the $\mathrm{SiO}_{2}$ gate dielectric-based $a$-IGZO TFT could be a faster device, whereas the $\mathrm{Ta}_{2} \mathrm{O}_{5}$ gate dielectric would be a good candidate for a higher reliability component with adequate surface treatment.
\end{abstract}

Keywords: $a$-IGZO; thin-film transistor; e-beam; gate dielectric; reliability

\section{Introduction}

Recent studies have been focused on several transparent conducting oxides (TCO), such as zinc oxide $(\mathrm{ZnO})$, indium zinc oxide (IZO), amorphous zinc tin oxide ( $a$-ZTO) and amorphous indium gallium zinc oxide ( $a$-IGZO) [1-3]. These materials showed advantages, such as an easy film coating process, better surface morphology, and electrical stability during operation. Among them, $a$-IGZO has been proven to be a promising material because of its high mobility and transparency [4]. It exhibited a smooth surface quality when deposited at room temperature [5]. Therefore, this oxide material has been investigated for the active channel layers in thin-film transistors (TFTs). In addition, $a$-IGZO TFTs can be fabricated on silicon wafer, glass, and also flexible organic substrates. The prevailing amorphous silicon ( $a$-Si:H) exhibits a low carrier mobility $\left(0.5-1 \mathrm{~cm}^{2} / \mathrm{V} \cdot \mathrm{s}\right)$, while the polycrystalline silicon (poly-Si) requires high-temperature fabrication processes $\left(>500{ }^{\circ} \mathrm{C}\right)[6,7]$. However, recent studies have found that the performance of TFTs is very much dependent upon the gate dielectric material and its deposition method [8]. 
Silicon dioxide $\left(\mathrm{SiO}_{2}\right)$ has been used as the gate dielectric in $a$-IGZO TFTs because of its thermal stability and smooth surface morphology. Most of the reported results achieved mobility for smaller channel dimension-based $a$-IGZO TFTs $<20 \mathrm{~cm}^{2} / \mathrm{V} \cdot \mathrm{s}$, using various coating methods, such as thermal growth, sputtering, and plasma-enhanced chemical vapor deposition (PECVD) [9-12]. On the other hand, $a$-IGZO TFTs with a bigger channel size have been studied using e-beam deposited $\mathrm{SiO}_{2}$ gate dielectric. The electrical performances could be significantly improved after employing plasma treatment on the gate dielectric [13].The atomic layer deposited (ALD) $\mathrm{SiO}_{2}$ gate dielectric was also reported on $a$-IGZO TFTs that could maintain a good stability under a negative gate bias stress, while exhibiting very high field-effect mobility without any post-annealing [14].

In the literature, several high-k gate dielectrics have been introduced to increase the mobility and reliability of $a$-IGZO TFTs. High-k gate dielectrics can provide a high gate capacitance and low leakage current with an equivalent oxide thickness, and the drivability can be further improved. For example, Chiu et al. reported a room-temperature deposited $a$-IGZO channel with tantalum pentoxide $\left(\mathrm{Ta}_{2} \mathrm{O}_{5}\right.$, high-k $\sim 29$ ) exhibited field-effect mobility of $61.5 \mathrm{~cm}^{2} / \mathrm{V} \cdot \mathrm{s}$ [15]. Qian et al. achieved a mobility of $30.1 \mathrm{~cm}^{2} / \mathrm{V}$.s for $a$-IGZO TFTs using $\mathrm{Ta}_{2} \mathrm{O}_{5}$ dielectricwithlanthanum (La) incorporation [16]. However, critical issues related to the threshold voltage variation along the channel width, bias-stress instability, and device reliability are still challenging, which can seriously influence the practical applications of $a$-IGZO TFTs. There are a number of reports on $a$-IGZO TFTs with a comparative study of different dielectric materials prepared by the same coating technology. Lee et al. performed a study on the electrical characteristics and device instabilities in $a$-IGZO TFTs with four different high-k gate dielectrics $\left(\mathrm{Al}_{2} \mathrm{O}_{3}, \mathrm{HfO}_{2}, \mathrm{Ta}_{2} \mathrm{O}_{5}\right.$, and $\left.\mathrm{ZrO}_{2}\right)$, deposited with the radio frequency (RF) sputtering method [8]. They concluded that higher $\mathrm{k}$ dielectric $\mathrm{ZrO}_{2}$ is the most preferable candidate in terms of bias stress, mobility, or current on-off ratio. The highest achieved mobility was $10.2 \mathrm{~cm}^{2} / \mathrm{V} \cdot \mathrm{s}$ for high-k dielectric $\mathrm{ZrO}_{2}$. Lin et al. investigated $a$-IGZO TFTs using different high-k gate dielectric materials, such as silicon nitride $\left(\mathrm{Si}_{3} \mathrm{~N}_{4}\right)$ and aluminum oxide $\left(\mathrm{Al}_{2} \mathrm{O}_{3}\right)$, at a low temperature process $\left(<300{ }^{\circ} \mathrm{C}\right)$ and compared them with low-temperature $\mathrm{SiO}_{2}$ [17]. However, they achieved a mobility $<10 \mathrm{~cm}^{2} / \mathrm{V} \cdot \mathrm{s}$ and had a large variation of electrical properties in a stressed situation. Therefore, there are still some obstacles to this oxide being useful in real applications, especially with a combination of different channel widths and different gate dielectrics using different deposition methods. The performances of $a$-IGZO TFTs with different combinations of gate dielectric and channel width have not been clearly investigated. The TFT performances could be affected with conjugate effects because of the variation in electric field, surface roughness, and insulating property. In addition, the threshold voltage variation along different channel widths with e-beam deposited gate dielectric remains questionable. It is, thus, very important to investigate the reliability characteristics with different dielectrics.

In this report, the comparative performances of $a$-IGZO TFTs were studied with e-beam deposited gate dielectrics of $\mathrm{SiO}_{2}, \mathrm{Si}_{3} \mathrm{~N}_{4}$, and $\mathrm{Ta}_{2} \mathrm{O}_{5}$. A distribution of threshold voltage was carried out with three different channel width sizes for each gate dielectric. The influence by combination of channel width and gate dielectric on $a$-IGZO TFTs electrical properties was thus investigated. The reliability performances with a respective variation in threshold voltage and drain current of $a$-IGZO TFTs under the stress voltage of $3 \mathrm{~V}$ for $1000 \mathrm{~s}$ measurement were evaluated. The mechanism explained the variation in threshold voltage and drain current for the various dielectric systems. In addition, the threshold voltage variation along the 500-1500 $\mu \mathrm{m}$ channel width decreased from $\mathrm{SiO}_{2}$, then $\mathrm{Si}_{3} \mathrm{~N}_{4}$, to $\mathrm{Ta}_{2} \mathrm{O}_{5}$, because of the increased insulating property and density of capacitance. The e-beam deposited high- $\mathrm{k}$ dielectric $\mathrm{Ta}_{2} \mathrm{O}_{5}$ exhibited the highest stability due to its high capacitance density. Moreover, this study classified that $\mathrm{Ta}_{2} \mathrm{O}_{5}$ gate dielectric would be a good candidate for long-term reliability components.

\section{Materials and Methods}

In the experiments, sputter-deposited 100nm indium tin oxide (ITO)-coated glass, with a sheet resistance of $15 \mathrm{ohm} / \mathrm{sq}$, was used as the substrates. The substrates were washed in an ultrasonic bath 
with acetone, isopropyl alcohol, and de-ionized water for $15 \mathrm{~min}$ in each step. The substrates were then dried by $\mathrm{N}_{2}$ gun and a hot plate at $120^{\circ} \mathrm{C}$ for $1 \mathrm{~h}$ before use. After that, a $1 \mathrm{~mm} \times 2 \mathrm{~cm}$ area size from one side was covered using a vacuum tape with a shadow mask on the common bottom gate of ITO. The system was designed to make patterns for gate dielectrics and the $a$-IGZO layer for the relatively large channels. Samples with different types of gate dielectric materials were deposited by an e-beam evaporator system using an $\mathrm{SiO}_{2}, \mathrm{Si}_{3} \mathrm{~N}_{4}$, and $\mathrm{Ta}_{2} \mathrm{O}_{5}$ source, respectively. Before the evaporation of each of the three gate dielectric materials, the e-beam chamber vacuum base pressure was about $8 \times 10^{-6}$ Torr $\left(10.6 \times 10^{-4} \mathrm{~Pa}\right)$. However, the chamber pressure during the evaporation increased to the order of $2-4 \times 10^{-5}$ Torr $\left(2.6-5.3 \times 10^{-3} \mathrm{~Pa}\right)$. The deposition rate was about $1-10 \mathrm{~nm} / \mathrm{s}$. The temperature of the e-beam chamber was varied at $23-30{ }^{\circ} \mathrm{C}, 23-40{ }^{\circ} \mathrm{C}$, and $23-45^{\circ} \mathrm{C}$ during the film deposition of $\mathrm{SiO}_{2}, \mathrm{Si}_{3} \mathrm{~N}_{4}$, and $\mathrm{Ta}_{2} \mathrm{O}_{5}$, respectively. This was likely caused by the different melting points of the materials $\left(\mathrm{SiO}_{2} \sim 1423{ }^{\circ} \mathrm{C}, \mathrm{Si}_{3} \mathrm{~N}_{4} \sim 1700{ }^{\circ} \mathrm{C}\right.$, and $\left.\mathrm{Ta}_{2} \mathrm{O}_{5} \sim 1875{ }^{\circ} \mathrm{C}\right)$ due to the heating effect of the e-beam sources $[18,19]$. The deposition current was also varied for $\mathrm{SiO}_{2}, \mathrm{Si}_{3} \mathrm{~N}_{4}$, and $\mathrm{Ta}_{2} \mathrm{O}_{5}$ at about 5-6, 16-17, and 20-21 amps (A), respectively, at a fixed voltage of $5 \mathrm{kV}$. The thickness of each gate dielectric layer was kept the same at $\sim 200 \mathrm{~nm}$. There was no intentional substrate heating for all cases. Additionally, all dielectric layers were deposited by the e-beam evaporator on $\mathrm{p}+\mathrm{Si}$ at the same instant to evaluate the density of capacitance with fabricated metal-insulator-semiconductor (MIS) capacitors. Then, $a$-IGZO $40 \mathrm{~nm}$ films were deposited on the bi-layers of $\mathrm{SiO}_{2} / \mathrm{ITO}$ glass, $\mathrm{Si}_{3} \mathrm{~N}_{4} / \mathrm{ITO}$ glass, and $\mathrm{Ta}_{2} \mathrm{O}_{5} /$ ITO glass by RF sputtering. The deposition power was fixed at $70 \mathrm{~W}$ and the pressure was about $3 \mathrm{~m}$ Torr (0.4 Pa). The Ar/O 2 inlet gas ratio was 50:1 for all the different gate dielectric-based samples. All the deposition conditions were kept the same at all times to avoid any other uncertain effect. After that, $100 \mathrm{~nm} \mathrm{Al} \mathrm{film} \mathrm{was} \mathrm{coated} \mathrm{by} \mathrm{a} \mathrm{thermal} \mathrm{evaporator} \mathrm{system} \mathrm{and} \mathrm{then} \mathrm{patterned} \mathrm{to}$ form the source and drain of the thin-film transistor, followed by photolithography and a lift process. A cross-section scanning electron microscope (SEM, Hitachi S-5000, Tokyo, Japan) image is presented here to qualify the thickness of multiple films in Figure 1. A layer-by-layer structure can be observed. The channel width was varied at $500 \mu \mathrm{m}, 1000 \mu \mathrm{m}$, and $1500 \mu \mathrm{m}$, while the channel length was fixed at $200 \mu \mathrm{m}$. Figure 2 shows a schematic representation of the final device structure. In addition, $a$-IGZO films were grown on clean bare glass to be used for an evaluation of the physical characteristics of the surface roughness by atomic force microscopy (AFM, Park System, XE-70, Santa Clara, CA, USA) and the optical transmittance spectra by a UV spectrometer (Jasco, Tokyo, Japan, ISN-723). The three different MIS capacitors were then measured using a 4284A precision LCR (inductance, capacitance, and resistance) meter at constant frequency of $1 \mathrm{MHz}$. The TFT device electrical properties, such as transfer characteristics, output characteristics, and bias stress characteristics, were evaluated with a semiconductor parameter analyzer (B1500A, Agilent, Santa Clara, CA, USA).

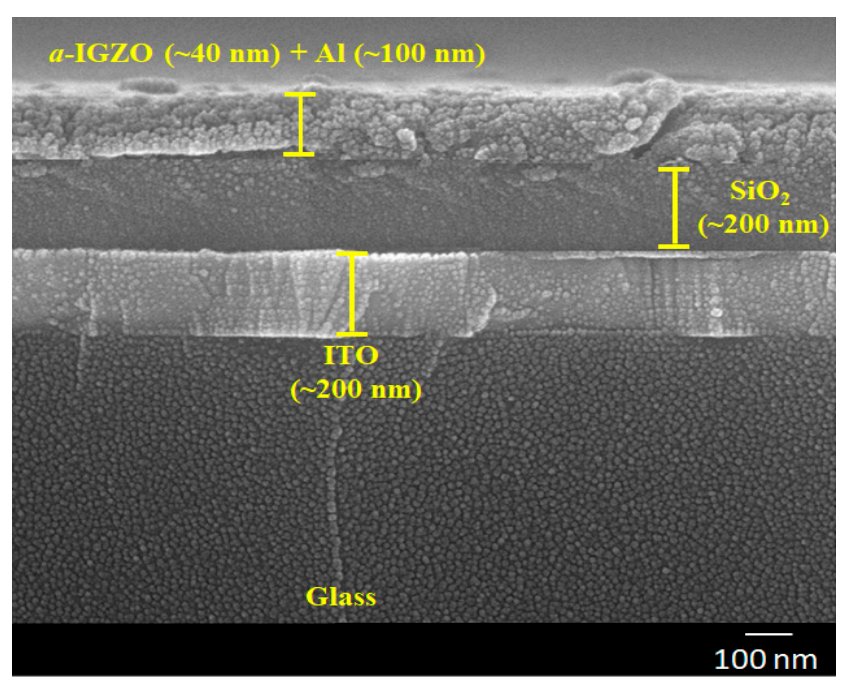

Figure 1. A cross-section SEM image for the multiple films on glass substrate. 


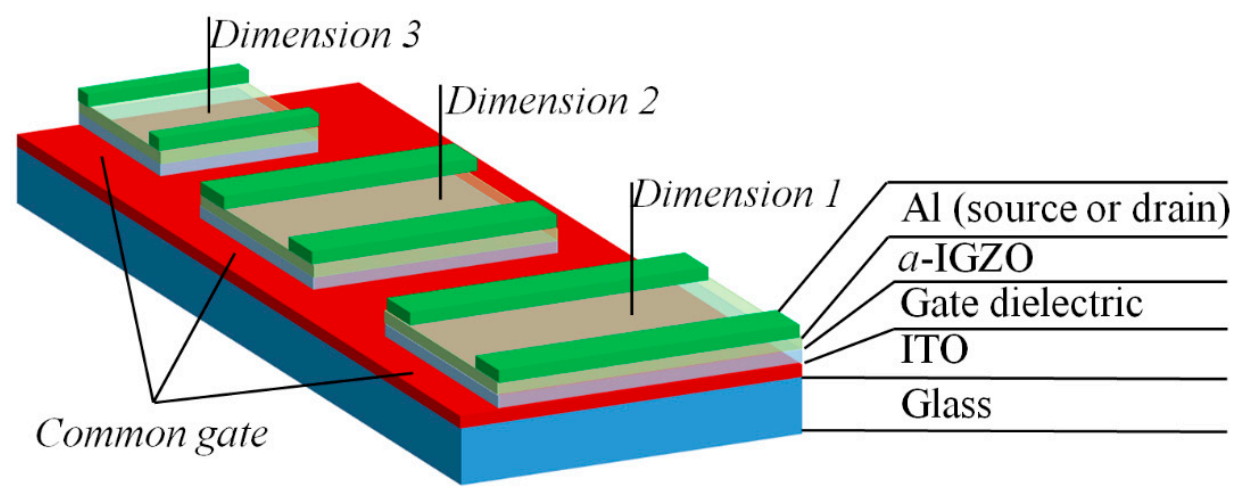

Figure 2. A schematic representation of the multiple dimension device structure.

\section{Results and Discussion}

The optical transmittance spectra for the as-deposited $a$-IGZO films on clean bare glass are shown in Figure 3 with the optimized argon to oxygen flow rate 50:1. The average transmittance of $a$-IGZO films exhibited above $80 \%$ in the visible and near-infrared range (VNIR, wavelength range $400 \mathrm{~nm}$ to $1000 \mathrm{~nm}$ ). The band gap energy of the $a$-IGZO film could be derived using a plotting method [20] The band gap energy of films was thus obtained at about $3.49 \mathrm{eV}$ by extrapolating the straight-line portion of $(\alpha h v)^{2}$ vs. $h v$ plots to the energy axis. Here, $h$ and $v$ represent for the Planck constant and the radiation frequency.

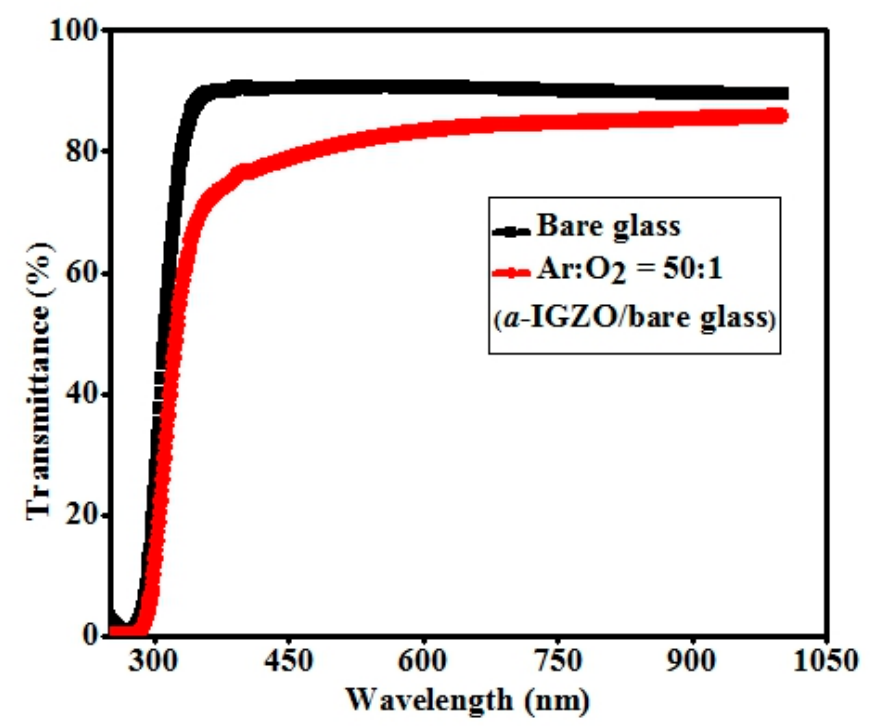

Figure 3. Optical transmission spectra of RF sputtered as-deposited $a$-IGZO films on clean bare glass.

The top surface morphology of the e-beam deposited dielectric layers were investigated using AFM image analysis and the as-deposited $\mathrm{SiO}_{2}$ film on ITO glass substrate image is hereby shown in Figure 4. The surface roughness (RMS) $\mathrm{Rq}$ values of the e-beam deposited $\mathrm{SiO}_{2}, \mathrm{Si}_{3} \mathrm{~N}_{4}$, and $\mathrm{Ta}_{2} \mathrm{O}_{5}$ were $3.94 \mathrm{~nm}, 4.06 \mathrm{~nm}$, and $4.11 \mathrm{~nm}$, respectively. The high-k dielectric $\mathrm{Si}_{3} \mathrm{~N}_{4}$ and $\mathrm{Ta}_{2} \mathrm{O}_{5}$ had a slightly higher surface roughness than the $\mathrm{SiO}_{2}$. This has been attributed to the higher heating effect by the larger temperature variation range, for $\mathrm{Ta}_{2} \mathrm{O}_{5} \sim 22^{\circ} \mathrm{C}, \mathrm{Si}_{3} \mathrm{~N}_{4} \sim 17^{\circ} \mathrm{C}$, and $\mathrm{SiO}_{2}$ only $\sim 7^{\circ} \mathrm{C}$, and also possibly an enhanced pressure variation during the film deposition process. 


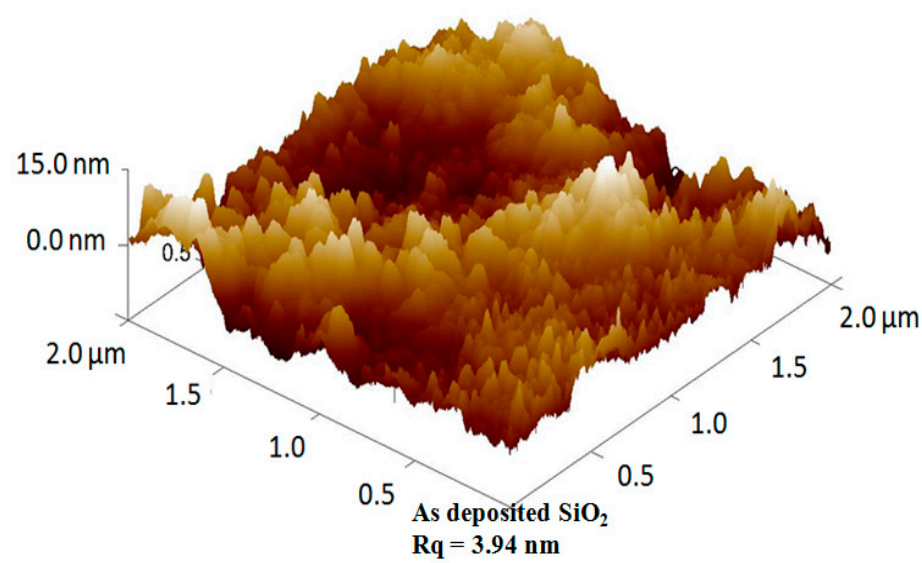

Figure 4. Atomic force microscopy (AFM) image of the e-beam deposited $\mathrm{SiO}_{2}$ film on indium tin oxide (ITO) glass substrate.

The capacitance variation of the e-beam deposited dielectric materials was measured on $\mathrm{p}^{+} \mathrm{Si}$ wafer with the MIS structures. The capacitance vs. applied voltage characteristics with a sweep voltage of $-5 \mathrm{~V}$ to $+5 \mathrm{~V}$ are shown in Figure 5 . The maximum capacitance density $\left(C_{\mathrm{ox}}\right)$ was achieved at the accumulation region at about $4 \mathrm{nF} / \mathrm{cm}^{2}, 16.9 \mathrm{nF} / \mathrm{cm}^{2}$, and $34.1 \mathrm{nF} / \mathrm{cm}^{2}$ for the corresponding $\mathrm{SiO}_{2}, \mathrm{Si}_{3} \mathrm{~N}_{4}$, and $\mathrm{Ta}_{2} \mathrm{O}_{5}$ gate dielectric materials. The e-beam deposited $\mathrm{Ta}_{2} \mathrm{O}_{5}$ gate dielectric material showed a much higher insulating property compared to $\mathrm{SiO}_{2}$ and $\mathrm{Si}_{3} \mathrm{~N}_{4}$. Nevertheless, much higher capacitance density dielectrics can be further explored by multiple oxides using more sophisticated deposition techniques.

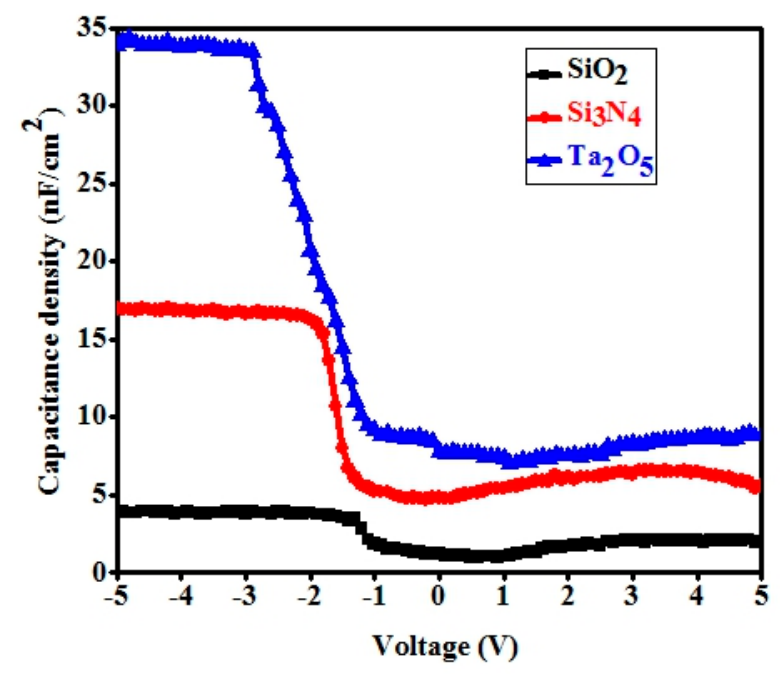

Figure 5. Capacitance density vs. voltage characteristics of the metal-insulator-semiconductor (MIS) capacitor with gate dielectric $\mathrm{SiO}_{2}, \mathrm{Si}_{3} \mathrm{~N}_{4}$, and $\mathrm{Ta}_{2} \mathrm{O}_{5}$ deposited on $\mathrm{p}+\mathrm{Si}$ wafer.

The channel width dependent transfer characteristics of the $a$-IGZO TFTs with the different e-beam deposited gate dielectrics of $\mathrm{SiO}_{2}, \mathrm{Si}_{3} \mathrm{~N}_{4}$, and $\mathrm{Ta}_{2} \mathrm{O}_{5}$ are shown in Figure 6. The characteristics could have also been represented for the channel size width of $500 \mu \mathrm{m}, 1000 \mu \mathrm{m}$, and $1500 \mu \mathrm{m}$, respectively, at the fixed channel length of $200 \mu \mathrm{m}$. The transfer characteristics of $a$-IGZO TFTs were significantly changed with the various gate dielectric materials as well as with the various channel widths in TFTs. Nevertheless, the performances of the nine different types of TFTs could be compared by evaluating their basic performance parameters, such as field effect mobility $\left(\mu_{\text {fet }}\right)$, threshold voltage $\left(V_{\text {th }}\right)$, sub-threshold swing voltage $(S S)$, and on-current to the off-current ratio $\left(I_{\text {on }} / I_{\text {off }}\right)$. 


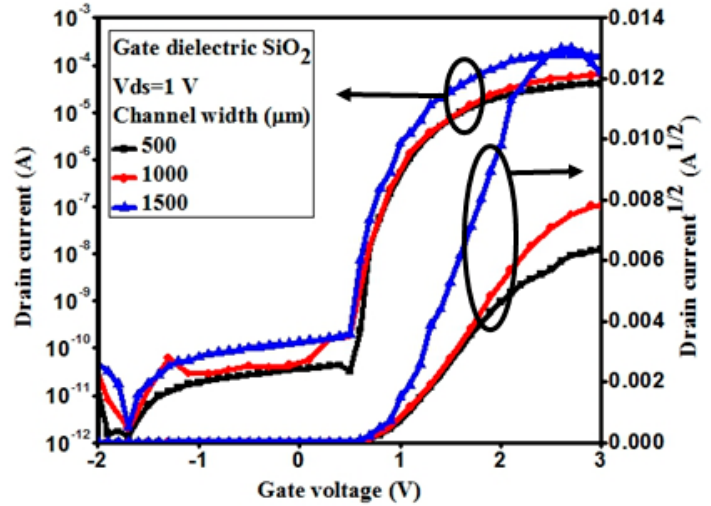

(a)

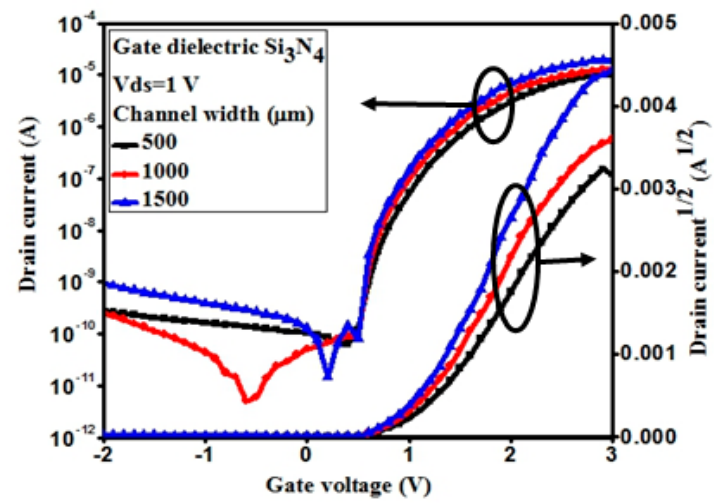

(b)

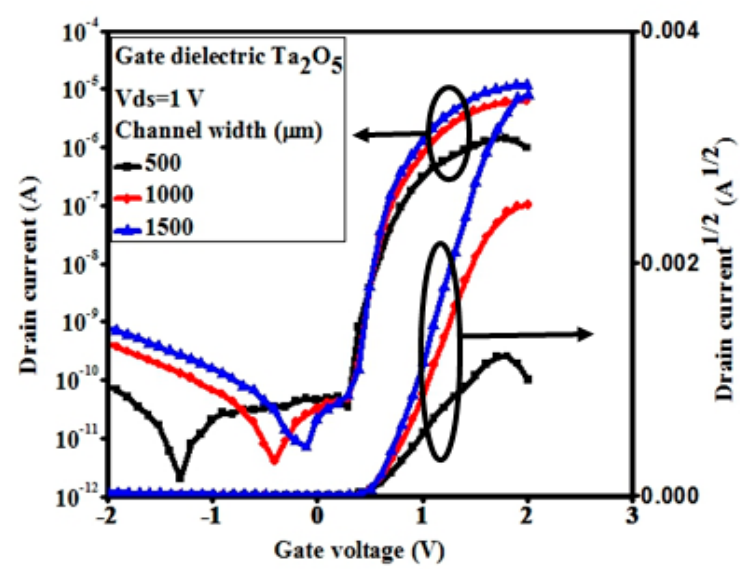

(c)

Figure 6. Typical transfer characteristics of the $a$-IGZO-based thin-film transistors (TFTs) with gate dielectric (a) $\mathrm{SiO}_{2}$, (b) $\mathrm{Si}_{3} \mathrm{~N}_{4}$, and (c) $\mathrm{Ta}_{2} \mathrm{O}_{5}$ at different channel widths of 500, 1000, and $1500 \mu \mathrm{m}$. The drain voltage was $1 \mathrm{~V}$, and the right-hand side graph shows the characteristics of $\mathrm{I}_{\mathrm{d}}{ }^{1 / 2}$ vs. voltage to determine the threshold voltages.

Tables 1-3 summarize the evaluated TFT performance parameters for each of the gate dielectric material systems used in this study. The drain to source voltage $V_{\mathrm{ds}}$ keeps a constant at $1 \mathrm{~V}$ for all samples. The capacitance density data have been derived for the three dielectric materials. The field effect mobility $\left(\mu_{\mathrm{fet}}\right)$ at the saturated regime has been derived by the following equation:

$$
u_{\mathrm{fet}}=\frac{\left(\frac{d \sqrt{I_{\mathrm{ds}}}}{d V_{\mathrm{gs}}}\right)^{2}}{\frac{1}{2} C_{\mathrm{ox}} \cdot\left(\frac{W}{L}\right) \cdot V_{\mathrm{ds}}}
$$

where $W$ is the width and $L$ is the length of TFT channel.The evaluated mobility $\mu_{\text {fet }}$ using the three gate-insulting materials $\mathrm{SiO}_{2}, \mathrm{Si}_{3} \mathrm{~N}_{4}$, and $\mathrm{Ta}_{2} \mathrm{O}_{5}$ is $27.9 \mathrm{~cm}^{2} / \mathrm{V} \cdot \mathrm{s}, 20.6 \mathrm{~cm}^{2} / \mathrm{V} \cdot \mathrm{s}$, and $12.1 \mathrm{~cm}^{2} / \mathrm{V} \cdot \mathrm{s}$, respectively, at the fixed channel width of $500 \mu \mathrm{m}$. The mobility has been extracted at agate voltage of 1.4 1.5 V. The evaluated data become $21.6 \mathrm{~cm}^{2} / \mathrm{V} \cdot \mathrm{s}, 13.5 \mathrm{~cm}^{2} / \mathrm{V} \cdot \mathrm{s}$, and $6.4 \mathrm{~cm}^{2} / \mathrm{V} \cdot \mathrm{s}$, respectively, at the channel width of $1000 \mu \mathrm{m}$ and they are $13.5 \mathrm{~cm}^{2} / \mathrm{V} \cdot \mathrm{s}, 8.8 \mathrm{~cm}^{2} / \mathrm{V} \cdot \mathrm{s}$, and $4.7 \mathrm{~cm}^{2} / \mathrm{V} \cdot \mathrm{s}$ at the fixed channel width of $1500 \mu \mathrm{m}$. It was immediately noted that the lower values in mobility were associated with the high-k dielectric $\mathrm{Si}_{3} \mathrm{~N}_{4}$ and $\mathrm{Ta}_{2} \mathrm{O}_{5}$-based $a$-IGZO TFTs. That was likely caused by the higher surface roughness of the as-deposited gate dielectric $\mathrm{Si}_{3} \mathrm{~N}_{4}(\mathrm{Rq} 4.06 \mathrm{~nm})$ and $\mathrm{Ta}_{2} \mathrm{O}_{5}(\mathrm{Rq} 4.11 \mathrm{~nm})$ films. Nevertheless, the performances of $a$-IGZO TFTs could be further enhanced with special treatment by high temperature annealing or plasma surface modification. In discussion, the mobility was much more dependent on the surface roughness of the e-beam deposited gate dielectric, rather than the insulating 
properties of film. It will be more necessary for a good high temperature annealing process to reduce the surface roughness before their use in $a$-IGZO TFTs application. On the other hand, the mobility of TFTs also depends on the channel width of TFTs for all dielectrics used in the study. The higher mobility can be achieved at lower channel dimension-based TFTs. The decreasing trend was observed for the three gate dielectric material systems.

Table 1. The performance parameters of $a$-IGZO TFTs with $\mathrm{SiO}_{2}$ gate dielectric.

\begin{tabular}{ccccc}
\hline Width $(\mu \mathrm{m})$ & $V_{\text {th }}(\mathrm{V})$ & $\boldsymbol{I}_{\text {on }} / I_{\text {off }}$ & $S S(\mathrm{~V} / \mathrm{dec})$ & $\boldsymbol{\mu}_{\text {fet }}\left(\mathrm{cm}^{2} / \mathrm{V} \cdot \mathbf{s}\right)$ \\
\hline 500 & 0.83 & $2.9 \times 10^{7}$ & 0.11 & 27.9 \\
1000 & 0.85 & $4.6 \times 10^{7}$ & 0.11 & 21.6 \\
1500 & 0.88 & $8.1 \times 10^{7}$ & 0.10 & 13.5 \\
\hline
\end{tabular}

Table 2. The performance parameters of $a$-IGZO TFTs with $\mathrm{Si}_{3} \mathrm{~N}_{4}$ gate dielectric.

\begin{tabular}{ccccc}
\hline Width $(\mu \mathrm{m})$ & $V_{\text {th }}(\mathrm{V})$ & $I_{\text {on }} / I_{\text {off }}$ & $S S(\mathrm{~V} / \mathrm{dec})$ & $\mu_{\text {fet }}\left(\mathrm{cm}^{2} / \mathrm{V} \cdot \mathbf{s}\right)$ \\
\hline 500 & 0.73 & $1.5 \times 10^{5}$ & 0.15 & 20.6 \\
1000 & 0.74 & $2.1 \times 10^{6}$ & 0.13 & 13.5 \\
1500 & 0.75 & $7.1 \times 10^{6}$ & 0.11 & 8.8 \\
\hline
\end{tabular}

Table 3. The performance parameters of $a$-IGZO TFTs with $\mathrm{Ta}_{2} \mathrm{O}_{5}$ gate dielectric.

\begin{tabular}{ccccc}
\hline Width $(\mu \mathrm{m})$ & $V_{\text {th }}(\mathrm{V})$ & $\boldsymbol{I}_{\text {on }} / I_{\text {off }}$ & $S S(\mathrm{~V} / \mathrm{dec})$ & $\mu_{\text {fet }}\left(\mathrm{cm}^{2} / \mathrm{V} \cdot \mathbf{s}\right)$ \\
\hline 500 & 0.48 & $7.1 \times 10^{5}$ & 0.14 & 12.1 \\
1000 & 0.49 & $2.1 \times 10^{5}$ & 0.11 & 6.4 \\
1500 & 0.50 & $1.6 \times 10^{6}$ & 0.10 & 4.7 \\
\hline
\end{tabular}

A high speed and low power operation are important for TFT applications. This characteristic could be evaluated by the sub-threshold swing voltage (SS) of $a$-IGZO TFTs. A smaller $S S$ value suggests device stability, higher mobility, and lower interfacial trap charge density. The evaluated sub-threshold swing voltage $S S$ that used the three gate insulting dielectrics $\mathrm{SiO}_{2}, \mathrm{Si}_{3} \mathrm{~N}_{4}$, and $\mathrm{Ta}_{2} \mathrm{O}_{5}$ are $0.11 \mathrm{~V} / \mathrm{dec}, 0.15 \mathrm{~V} / \mathrm{dec}$, and $0.14 \mathrm{~V} / \mathrm{dec}$, respectively, at the fixed channel width of $500 \mu \mathrm{m}$. The $S S$ data become $0.11 \mathrm{~V} / \mathrm{dec}, 0.13 \mathrm{~V} / \mathrm{dec}$, and $0.11 \mathrm{~V} / \mathrm{dec}$, respectively, at the channel width of $1000 \mu \mathrm{m}$, and $0.10 \mathrm{~V} / \mathrm{dec}, 0.11 \mathrm{~V} / \mathrm{dec}$, and $0.10 \mathrm{~V} / \mathrm{dec}$ at the channel width of $1500 \mu \mathrm{m}$. It was evidenced that the $S S$ values are shown lower for the $\mathrm{SiO}_{2}$-based $a$-IGZO TFTs when compared with the $\mathrm{Si}_{3} \mathrm{~N}_{4}-$ and $\mathrm{Ta}_{2} \mathrm{O}_{5}$-based $a$-IGZO TFTs. The tendencies are similarly shown from the lower to higher sizes devices. This result suggested a better interface region in the $\mathrm{SiO}_{2}$ gate dielectric and $a$-IGZO channel system. However, the variation became much smaller for the higher size devices with the channel width of $1500 \mu \mathrm{m}$. The interfacial region could be enhanced with a trap charge density by introducing high-k dielectric $\mathrm{Si}_{3} \mathrm{~N}_{4}$ and $\mathrm{Ta}_{2} \mathrm{O}_{5}$. Additionally, the interfacial characteristics could be improved with bigger channel width sizes for high-k-based gate dielectrics.

The comparative performances of $a$-IGZO TFTs with the e-beam deposited gate dielectric $\mathrm{SiO}_{2}$ ， $\mathrm{Si}_{3} \mathrm{~N}_{4}$, and $\mathrm{Ta}_{2} \mathrm{O}_{5}$ along the different channel width sizes were further investigated by evaluating the on-current to the off-current ratio. A significant variation was observed among all the $a$-IGZO TFTs with different gate dielectrics as well as different channel width sizes. The $I_{\text {on }} / I_{\text {off }}$ ratios were $2.9 \times 10^{7}, 1.5 \times 10^{5}$, and $7.1 \times 10^{5}$ for the $\mathrm{SiO}_{2}, \mathrm{Si}_{3} \mathrm{~N}_{4}$, and $\mathrm{Ta}_{2} \mathrm{O}_{5}$ TFT devices, respectively, at the fixed channel width of $500 \mu \mathrm{m}$. They became $4.6 \times 10^{7}, 2.1 \times 10^{6}$, and $2.1 \times 10^{5}$, respectively, at the channel width of $1000 \mu \mathrm{m}$, and $8.1 \times 10^{7}, 7.1 \times 10^{6}$, and $1.6 \times 10^{6}$ at the channel width of $1500 \mu \mathrm{m}$. The $I_{\text {on }} / I_{\text {off }}$ values were generally increased with the increasing channel width sizes. However, they were eventually decreased for the high-k gate dielectric $\mathrm{Si}_{3} \mathrm{~N}_{4}$ and $\mathrm{Ta}_{2} \mathrm{O}_{5}$ compared to the $\mathrm{SiO}_{2}$ samples. The noticeable variation in the off-current level and on-current level occurred. The lower off-current level or gate leakage current was achieved with an increased capacitance density corresponding to the 
gate dielectrics, whereas the opposite phenomena were observed for the on-current level situation. The results clearly indicated that the as-deposited e-beam high- $\mathrm{Si}_{3} \mathrm{~N}_{4}$ and $\mathrm{Ta}_{2} \mathrm{O}_{5}$ films could not improve the performances of $a$-IGZO TFTs because of the higher surface roughness. An improved annealing process and/or plasma treatment is required to reduce the surface roughness. On the other hand, the on-off current level increased with increased channel width, because of the increase in parasitic resistance between the channel surface and the source-drain electrode. Still, the distribution of the off-current level along the different channel width was increased for the gate dielectric $\mathrm{SiO}_{2}$ $\left(10^{-12}-10^{-11}\right), \mathrm{Si}_{3} \mathrm{~N}_{4}\left(10^{-11}-10^{-9}\right)$ to $\mathrm{Ta}_{2} \mathrm{O}_{5}\left(10^{-12}-10^{-9}\right)$. The wider scattering of the off-current level was likely caused by the increased surface roughness of $\mathrm{Si}_{3} \mathrm{~N}_{4}$ and $\mathrm{Ta}_{2} \mathrm{O}_{5}$.

It has been noted that the drain current dropped at high applied gate voltages for the low channel width TFTs. This is an indication of leakage current. The leakage current results are therefore derived and shown in Figure 7 for the three different channel widths of $\mathrm{SiO}_{2}$-based $a$-IGZO TFTs. The maximum gate leakage current was $40.5 \mathrm{nA}, 37.2 \mathrm{nA}$, and $20.8 \mathrm{nA}$ at the gate voltage of $3 \mathrm{~V}$, in correspondence to the channel width of $500 \mu \mathrm{m}, 1000 \mu \mathrm{m}$, and $1500 \mu \mathrm{m}$, respectively. It was thus clearly evidenced that the TFT gate leakage current would be effectively decreased with increasing channel width/length $(\mathrm{W} / \mathrm{L})$ ratio.

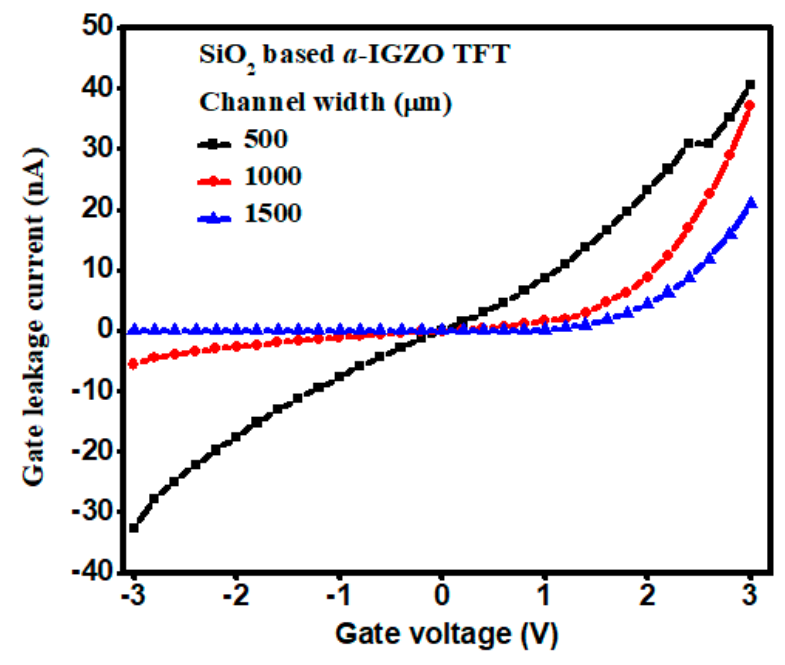

Figure 7. Gate leakage current for the $\mathrm{SiO}_{2}$-based $a$-IGZO TFTs.

The threshold voltages were calculated from the extrapolation of the $I_{\mathrm{ds}}{ }^{1 / 2}$ vs. $V_{g s}$ transfer characteristic curves. The $V_{\text {th }}$ values were $0.83 \mathrm{~V}, 0.73 \mathrm{~V}$, and $0.48 \mathrm{~V}$ for the gate dielectric $\mathrm{SiO}_{2}$, $\mathrm{Si}_{3} \mathrm{~N}_{4}$, and $\mathrm{Ta}_{2} \mathrm{O}_{5}$ samples, respectively, at the fixed channel width of $500 \mu \mathrm{m}$. They became $0.85 \mathrm{~V}$, $0.74 \mathrm{~V}$, and $0.49 \mathrm{~V}$, respectively, at the channel width of $1000 \mu \mathrm{m}$, and $0.88 \mathrm{~V}, 0.75 \mathrm{~V}$, and $0.50 \mathrm{~V}$ at the fixed channel width of $1500 \mu \mathrm{m}$. The high-k dielectric $\mathrm{Ta}_{2} \mathrm{O}_{5}$ and $\mathrm{Si}_{3} \mathrm{~N}_{4}$ were shown with lower threshold voltages than the $\mathrm{SiO}_{2}$ for each of the fixed-channel-width $a$-IGZO TFTs. The lower power consumption application by the high-k-based $a$-IGZO TFTs would be more suitable than that by the $\mathrm{SiO}_{2}$ gate dielectric. However, the threshold voltage was varied along the channel width sizes at the range of $0.05 \mathrm{~V}, 0.02 \mathrm{~V}$, and $0.02 \mathrm{~V}$, with the corresponding gate dielectric $\mathrm{SiO}_{2}, \mathrm{Si}_{3} \mathrm{~N}_{4}$, and $\mathrm{Ta}_{2} \mathrm{O}_{5}$, respectively. It should be noted that the variation of the threshold voltage along the channel width decreased with the increase in the insulating properties of dielectrics. Thus, more stable $a$-IGZO TFTs could be achieve using the high-k gate dielectrics $\mathrm{Ta}_{2} \mathrm{O}_{5}$ and $\mathrm{Si}_{3} \mathrm{~N}_{4}$, instead of using $\mathrm{SiO}_{2}$. The threshold voltages decreased with an increased capacitance density of materials, rather than by the effect of surface roughness of gate dielectrics. The smaller variation in threshold voltages along the channel width suggested better TFT candidates with respect to stability and reliability testing. Thus, it becomes interesting to discuss the stress measurement characteristics. 
The threshold voltage variation under positive bias stress (PBS) on different channel widths of $500 \mu \mathrm{m}$ and $1500 \mu \mathrm{m}$ with the e-beam deposited gate dielectric $\mathrm{SiO}_{2^{-}}, \mathrm{Si}_{3} \mathrm{~N}_{4^{-}}$, and $\mathrm{Ta}_{2} \mathrm{O}_{5}$-based $a$-IGZO TFTs are displayed in Figure 8. The threshold voltage shifted towards a positive direction for all types of $a$-IGZO TFTs using the stress voltage of $3 \mathrm{~V}$ for $1000 \mathrm{~s}$. However, the variation in the threshold voltage was much smaller for the high-k dielectric $\mathrm{Ta}_{2} \mathrm{O}_{5}$ samples. The threshold voltage shifted more positively in the order of $\mathrm{Ta}_{2} \mathrm{O}_{5}, \mathrm{Si}_{3} \mathrm{~N}_{4}$, and $\mathrm{SiO}_{2}$ gate dielectric-based TFTs along the stress time. It should also be noted that the trapping charge density decreased with increasing the channel width of the TFTs, in accordance with the smaller threshold voltage shift for $\mathrm{Ta}_{2} \mathrm{O}_{5}$ and $\mathrm{Si}_{3} \mathrm{~N}_{4}$ gate dielectric samples. The performances of the $a$-IGZO TFTs under a stress condition could be further improved with a suitable surface treatment process, such as a thermal annealing and plasma treatment process.

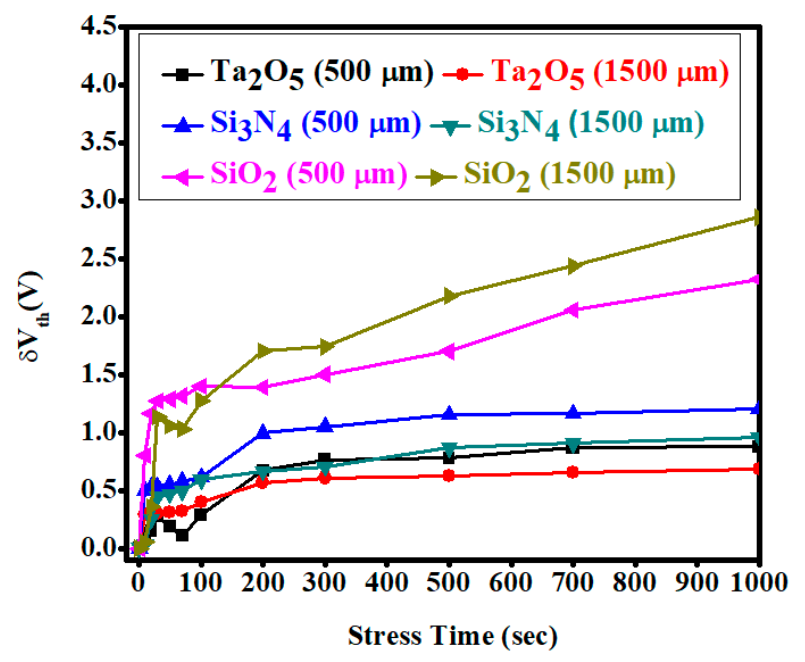

Figure 8. Change of threshold voltage variation under a positive bias stress (PBS) condition for 1000 $\mathrm{s}$ using gate dielectric $\mathrm{SiO}_{2}, \mathrm{Si}_{3} \mathrm{~N}_{4}$, and $\mathrm{Ta}_{2} \mathrm{O}_{5}$ at different channel widths of $500 \mu \mathrm{m}$ and $1500 \mu \mathrm{m}$. The positive stress voltage was $+3 \mathrm{~V}$.

The drain current variation under PBS on different channel widths of $500 \mu \mathrm{m}$ and $1500 \mu \mathrm{m}$ with the e-beam deposited gate dielectric $\mathrm{SiO}_{2-}, \mathrm{Si}_{3} \mathrm{~N}_{4}{ }^{-}$, and $\mathrm{Ta}_{2} \mathrm{O}_{5}$-based $a$-IGZO TFTs is shown in Figure 9 . The drain current decreased initially $(0-100 \mathrm{~s})$ with increasing the stress current, indicating the decreased on-off current ratio for all types of $a$-IGZO TFTs under a bias stress condition. The smaller variation of drain current was associated with the lower channel width size of $500 \mu \mathrm{m}$ for all gate dielectric TFTs. The variations were shown to be higher from $\mathrm{SiO}_{2}$ to $\mathrm{Si}_{3} \mathrm{~N}_{4}$ and $\mathrm{Ta}_{2} \mathrm{O}_{5}$, or $0.64 \mu \mathrm{A}$, $1.29 \mu \mathrm{A}$, and $1.35 \mu \mathrm{A}$, respectively. The results suggested that the quantitative value of the on-off current ratio could be decreased from $\mathrm{SiO}_{2}$ to $\mathrm{Si}_{3} \mathrm{~N}_{4}$ and $\mathrm{Ta}_{2} \mathrm{O}_{5}$ under PBS.

The comparative study among all the e-beam deposited gate dielectric materials $\mathrm{SiO}_{2}, \mathrm{Si}_{3} \mathrm{~N}_{4}$, and $\mathrm{Ta}_{2} \mathrm{O}_{5}$ exhibited potential performances in $a$-IGZO TFT application. However, the as-deposited $\mathrm{SiO}_{2}$ showed better basic performances in terms of mobility, current on-off ratio and sub-threshold voltages for all the dimension sizes. Nevertheless, its threshold voltage variation and threshold voltage shifting with a positive bias stress, along the channel width, was much bigger compared to those of e-beam deposited high-k gate dielectric $\mathrm{Si}_{3} \mathrm{~N}_{4}$ and $\mathrm{Ta}_{2} \mathrm{O}_{5}$. The reported performances of $a$-IGZO TFTs with high-k dielectric zirconium oxide $\left(\mathrm{ZrO}_{2}\right)$ at different channel widths were shown to be similar to the present study, where only a negligible threshold voltage variation along the channel width size was observed [21]. That is why those high-k dielectrics could still be more useful in real applications with adequate surface treatments. In the meantime, the width dependent characteristics of $a$-IGZO TFTs under stress voltage may produce the drain current variation because of the generation of a parasitic transistor, as a result of the high electric field at the insulator corner due to smaller insulator thickness [22]. Moreover, the basic, as well as the reliability performances of $\mathrm{Si}_{3} \mathrm{~N}_{4}$-and $\mathrm{Ta}_{2} \mathrm{O}_{5}$-based 
$a$-IGZO TFTs could be further improved using some surface treatment methods to reduce the surface roughness for future applications [12].

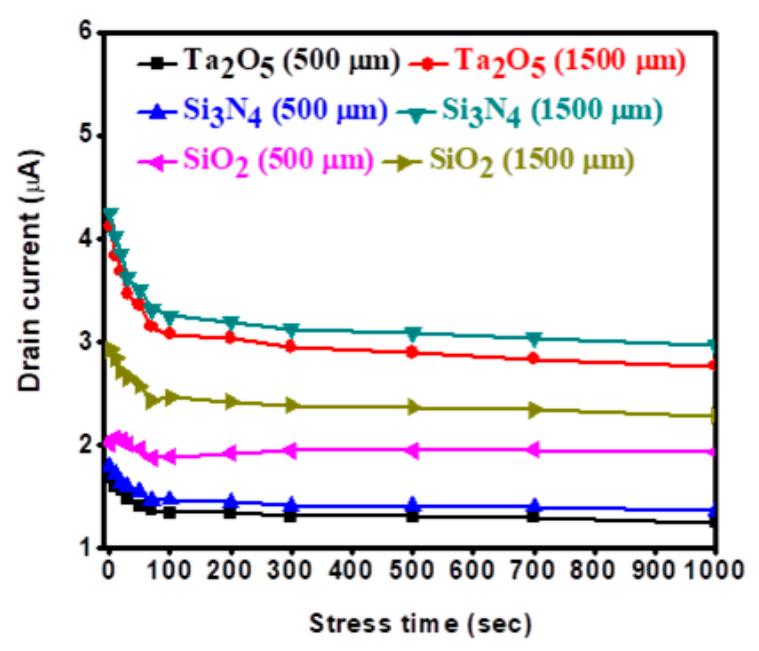

Figure 9. Drain current variation under a positive bias stress (PBS) condition for $1000 \mathrm{~s}$ with gate dielectric $\mathrm{SiO}_{2}, \mathrm{Si}_{3} \mathrm{~N}_{4}$, and $\mathrm{Ta}_{2} \mathrm{O}_{5}$ at different channel widths of $500 \mu \mathrm{m}$ and $1500 \mu \mathrm{m}$. The positive stress voltage was $+3 \mathrm{~V}$.

In addition, the output characteristics of the $a$-IGZO TFTs are shown in Figure 10 for the e-beam deposited gate dielectrics of $\mathrm{SiO}_{2}, \mathrm{Si}_{3} \mathrm{~N}_{4}$, and $\mathrm{Ta}_{2} \mathrm{O}_{5}$. The saturation drain current was decreased in the order of $\mathrm{SiO}_{2}, \mathrm{Si}_{3} \mathrm{~N}_{4}$, and $\mathrm{Ta}_{2} \mathrm{O}_{5}$, at all the applied gate voltages in the range of drain voltage of 0 to $6 \mathrm{~V}$ with a step voltage of $1 \mathrm{~V}$. All $a$-IGZO TFTs exhibited a good operation in the n-channel enhancement mode with a low drain current at zero gate voltage. The positive gate voltage enabled the production of electrons in the channel materials. It also exhibited clear pinch-off voltages and current saturation at the higher drain voltage. The drain current was observed to increase linearly with the drain voltage at a low gate voltage. This is in agreement with creating an ohmic contact of the source and drain. It has been proven that the TFTs met the standard field-effect transistor characteristics. Additionally, the decreased drain current at particular gate and drain voltages showed similar trends with the transfer characteristics of the $a$-IGZO TFTs with all three gate dielectrics along the channel width. The better ohmic contact achieved with gate dielectric $\mathrm{SiO}_{2}$ was due to the good interface contact of source and drain with the channel material surface, because smoother surface provided a lower parasitic effect [17]. On the other hand, the non-idealities in the output characteristics and a slightly negative degradation or hump effect were observed between the pinch-off and saturation regions. This phenomenon became more prominent with $\mathrm{Ta}_{2} \mathrm{O}_{5}$-based $a$-IGZO TFTs, likely due to interfacial resistance between layers. An additional surface treatment process for the gate dielectric layer could reduce this effect and achieve better ohmic contact. 


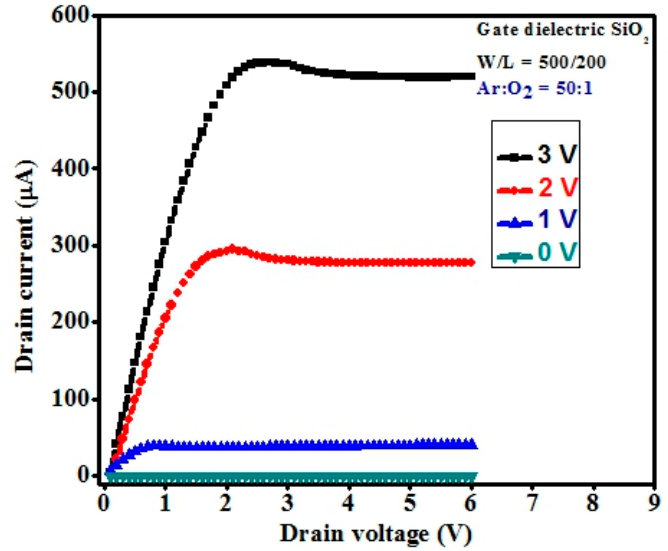

(a)

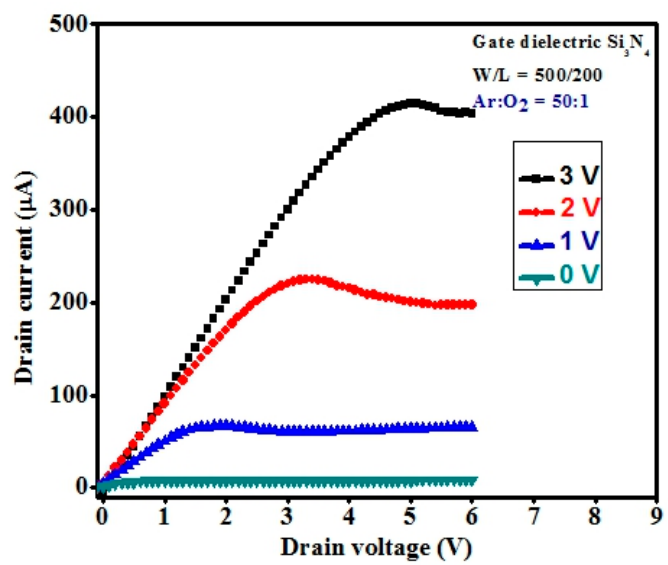

(b)

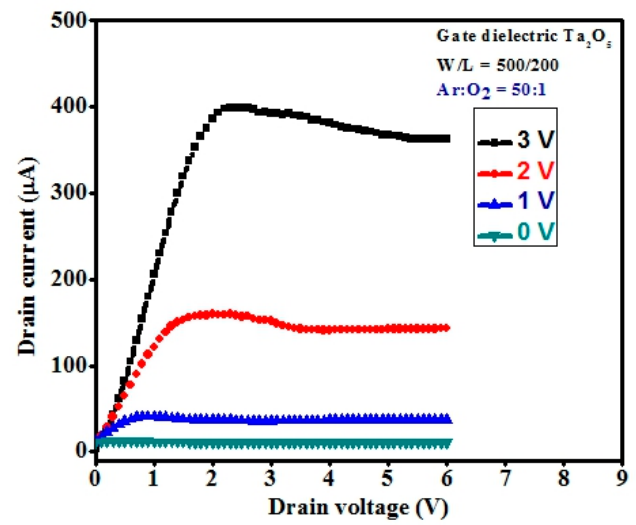

(c)

Figure 10. The output characteristics of the $a$-IGZO TFTs with different gate dielectric (a) $\mathrm{SiO}_{2},(\mathbf{b}) \mathrm{Si}_{3} \mathrm{~N}_{4}$, and $(c) \mathrm{Ta}_{2} \mathrm{O}_{5}$ at channel width of $500 \mu \mathrm{m}$. The gate voltage varied from $0 \mathrm{~V}$ to $3 \mathrm{~V}$ with an increased step voltage of $1 \mathrm{~V}$.

\section{Conclusions}

The performances of $a$-IGZO TFTs have been very much dependent upon the insulting properties of gate dielectric materials and the surface roughness. The e-beam as-deposited $\mathrm{SiO}_{2}$ presented the best basic electrical performances with a mobility of $27.7 \mathrm{~cm}^{2} / \mathrm{V} \cdot \mathrm{s}, 21.8 \mathrm{~cm}^{2} / \mathrm{V} \cdot \mathrm{s}$, and $13.3 \mathrm{~cm} / \mathrm{V} \cdot \mathrm{s}$ along different channel width sizes of $500 \mu \mathrm{m}, 1000 \mu \mathrm{m}$, and $1500 \mu \mathrm{m}$, respectively, because of the smoother surface properties. However, the reliability in terms of stress measurement revealed that the better stability with a smaller change in threshold voltage along the channel width should be achieved with an increased capacitance density of film, corresponding to the e-beam deposited gate dielectric $\mathrm{Ta}_{2} \mathrm{O}_{5}$. In addition, the results suggested that the low-cost, simple processing by an e-beam evaporator for depositing dielectric material $\mathrm{SiO}_{2}, \mathrm{Si}_{3} \mathrm{~N}_{4}$, and $\mathrm{Ta}_{2} \mathrm{O}_{5}$ could be used to obtain high-performance $a$-IGZO TFT devices. Special treatment on the surface to reduce surface roughness can further enhance the insulating properties. The channel width-dependent electrical performances for all types of $a$-IGZO TFTs clarified the threshold voltage variation at the room-temperature fabrication process with the $\mathrm{SiO}_{2}$ gate dielectric. This phenomenon could be avoided by replacing with high-k dielectrics, such as $\mathrm{Si}_{3} \mathrm{~N}_{4}$ and $\mathrm{Ta}_{2} \mathrm{O}_{5}$, where threshold voltage variation is much smaller compared tothat of $\mathrm{SiO}_{2}$. Therefore, this investigation of channel width-dependent electrical properties with different gate dielectrics should be applied for future development to design higher-performance $a$-IGZO TFTs.

Author Contributions: Investigation, G.W. and A.S.; Resources, D.C. and J.C.; Writing-Original Draft Preparation, A.S.; Writing-Review \& Editing, G.W. 
Funding: This work was supported in part by the Ministry of Science and Technology under research grants MOST105-2221-E182-059-MY3, and the CGMH financial support of CMRPG2H0291 and CMRP246.

Conflicts of Interest: The authors declare no conflict of interest.

\section{References}

1. Wang, J.L.; Yang, P.Y.; Juang, M.H.; Hsieh, T.Y.; Hwang, C.C.; Juan, C.P.; Lee, I.C. Zinc oxide thin-film transistors fabricated via low-temperature hydrothermal method. Surf. Coat. Tech. 2013, 231, 428-432. [CrossRef]

2. Martins, J.; Bahubalindruni, P.; Rovisco, A.; Kiazadeh, A.; Martins, R.; Fortunado, E.; Barquinha, P. Bias stress and temperature impact on InGaZnO TFTs and circuits. Materials 2017, 10, 680. [CrossRef] [PubMed]

3. Sittinger, V.; Pflug, A.; Schulz, C.; Siemers, M.; Melzig, T.; Meyer, B.; Kronenberger, A.; Berghaus, J.O.; Bosscher, W.D. Growth condition of amorphous ZTO films from rotatable targets. Surf. Coat. Tech. 2015, 267, 75-80. [CrossRef]

4. Kim, K.S.; Ahn, C.H.; Kang, W.J.; Cho, S.W.; Jung, S.H.; Yoon, D.H.; Cho, H.K. An all oxide-based imperceptible thin-film transistor with humidity sensing properties. Materials 2017, 10, 530. [CrossRef] [PubMed]

5. Wu, J.; Shi, J.; Dong, C.; Zou, Z.; Chen, Y.; Zhou, D.; Hu, Z.; Zhan, R. Effect of active layer deposition temperature on the performance of sputtered amorphous In-Ga-Zn-O thin film transistors. J. Semiconductors 2014, 35, 014003. [CrossRef]

6. Nomura, K.; Ohta, H.; Takagi, A.; Kamiya, T.; Hirano, M.; Hosono, H. Room-temperature fabrication of transparent flexible thin-film transistors using amorphous oxide semiconductors. Nature 2004, 432, 488-492. [CrossRef] [PubMed]

7. Ohsawa, H.; Sasaki, S.; Hara, A. Controllability of self-aligned four-terminal planar embedded metal double-gate low-temperature polycrystalline-silicon thin-film transistors on a glass substrate. Jpn. J. Appl. Phys. 2016, 55, 03CC01. [CrossRef]

8. Lee, I.K.; Lee, S.W.; Gu, J.G.; Kim, K.S.; Cho, W.J. Comparative study of device performance and reliability in amorphous InGaZnO thin-film transistors with various high-k gate dielectrics. Jpn. J. Appl. Phys. 2013, 52, 06GE05. [CrossRef]

9. Chen, T.; Ishihara, R.; Beenakker, K. High quality $\mathrm{SiO}_{2}$ deposited at $80^{\circ} \mathrm{C}$ by inductively coupled plasma enhanced CVD for flexible display application. Electrochem. Solid St. 2010, 13, J89-J91. [CrossRef]

10. Jun, S.I.; McKnight, T.E.; Melechko, A.V.; Simpson, M.L.; Rack, P.D. Characterisation of reactively sputtered silicon oxide for thin-film transistor fabrication. Electron. Lett. 2005, 41, 822-823. [CrossRef]

11. Hsu, C.M.; Tzou, W.C.; Yang, C.F.; Liou, Y.J. Investigation of the high mobility IGZO thin films by using co-sputtering method. Materials 2015, 8, 2769-2781. [CrossRef]

12. Hwang, Y.H.; . Jeon, J.H; Seo, S.J.; Bae, B.S. Solution-processed, high performance aluminum indium oxide thin-film transistors fabricated at low temperature. Electrochem. Solid St. 2009, 12, H336-H339. [CrossRef]

13. Wu, G.M.; Sahoo, A.K.; Lin, J.Y. Effects of e-beam deposited gate dielectric layers with atmospheric pressure plasma treatment for IGZO thin-film transistors. Surf. Coat. Tech. 2016, 306, 151-158. [CrossRef]

14. Zheng, L.L.; Ma, Q.; Wang, Y.H.; Liu, W.J.; Ding, S.J.; Zhang, D.W. High-performance unannealed a-InGaZnO TFT with an atomic-layer-deposited $\mathrm{SiO}_{2}$ insulator. IEEE Electr. Device L. 2016, 37, 743-746. [CrossRef]

15. Chiu, C.J.; Chang, S.P.; Chang, S.J. High-performance a-IGZO thin-film transistor using $\mathrm{Ta}_{2} \mathrm{O}_{5}$ gate dielectric. IEEE Electr. Device L. 2010, 31, 1245-1247.

16. Qian, L.X.; Liu, X.Z.; Han, C.Y.; Lai, P.T. Improved performance of amorphous InGaZnO thin-film transistor with $\mathrm{Ta}_{2} \mathrm{O}_{5}$ gate dielectric by using La incorporation. IEEE T. Device. Mat. Re. 2014, 14, 1056-1060. [CrossRef]

17. Lin, Y.H.; Chou, J.C. Interface study on amorphous indium gallium zinc oxide thin film transistors using high-k gate dielectric materials. J. Nanomater. 2015, 2015, 782786. [CrossRef]

18. Carter, C.B.; Norton, M.G. Ceramic Materials: Science and Engineering; Springer: New York, NY, USA; Heidelberg, Germany; Dordrecht, The Netherlands; London, UK, 2013; p. 644. ISBN 978-1-4614-3523-5.

19. Ali, S. Preparation, Characterization and Properties of Nitrogen Rich Glasses in Alkaline Earth-Si-O-N Systems. Doctoral Thesis, Department of Physical, Inorganic and Structural Chemistry, Stockholm University, Stockholm, Sweden, 2009.

20. Tauc, J.; Grigorovici, R.; Vancu, A. Optical properties and electronic structure of amorphous germanium. Phys. Stat. Sol. 1966, 15, 627-633. [CrossRef] 
21. Lee, J.S.; Chang, S.; Koo, S.M.; Lee, S.Y. High-performance $a$-IGZO TFT with $\mathrm{ZrO}_{2}$ gate dielectric fabricated at room temperature. IEEE Electr. Device L. 2010, 31, 225-227.

22. Kim, Y.M.; Jeong, K.S.; Yun, H.J.; Yang, S.D.; Lee, S.Y.; Lee, H.D.; Lee, G.W. Electrical instabilities in amorphous InGaZnO thin film transistors with $\mathrm{Si}_{3} \mathrm{~N}_{4}$ and $\mathrm{Si}_{3} \mathrm{~N}_{4} / \mathrm{Al}_{2} \mathrm{O}_{3}$ gate dielectrics. Jpn. J. Appl. Phys. 2012, 51, 09MF10. [CrossRef] 